\title{
MEDICINA E SAÚDE EM O NASCIMENTO DA CLÍNICA DE MICHEL FOUCAULT
}

\author{
MEDICINE AND HEALTH IN THE BIRTH OF THE CLINIC BY MICHEL FOUCAULT
}

Rosele Branco*

\begin{abstract}
RESUMO
Uma leitura de $O$ nascimento da clínica, de Michel Foucault, especialmente do capítulo "Uma consciência política", traz à tona um dos aspectos que constituiu o saber médico, o qual seria justamente a preocupação com a saúde da população. Conforme descrito por Foucault, a dispersão do discurso médico para o espaço social trouxe implicações para a racionalidade médica que ainda nos atingem na atualidade. Este artigo pretende acompanhar as análises arqueológicas de Foucault nesse livro e estabelecer os principais pontos de relevo e as pontes para as análises futuras em sua trajetória filosófica. Entre os pontos, podem-se destacar a instituição de uma medicina higienista do estado, as estatísticas, a necessidade de formar médicos, as relações estratégicas. Vai-se concluir o artigo com considerações finais acerca da instauração do discurso médico nas suas contingências históricas; acerca da constituição dos próprios médicos nas faculdades e corporações; e dos vínculos com os estudos posteriores de Foucault com o que ele denominará biopolítica.
\end{abstract}

PALAVRAS-CHAVE: arqueologia; Foucault; Nascimento da clínica; medicina; saúde.

\begin{abstract}
A reading of The Birth of the Clinic by Michel Foucault, especially of the chapter "A Political Consciousness", brings up one of the aspects that constituted the medical knowledge that is precisely the concern for the health of the population. As described by Foucault, the dispersion of medical discourse into the social space has brought implications for medical rationality that still affect us today. The article intends to follow Foucault's archaeological analyses in this book and establish the main points of importance and bridges for future analyses in his philosophical trajectory. Among the points, can be highlighted the institution of a state hygienist medicine, statistics, the need to train doctors, the strategic relations. It can be concluded with considerations about the constitution of the medical discourse and its historical contingencies; about the constitution of physicians themselves in colleges and corporations; and the links with Foucault's later studies on what he will call biopolitics.
\end{abstract}

KEYWORDS: archaeology; Foucault; Birth of the clinic; medicine; health.

\footnotetext{
Mestra e Doutora em Filosofia pela PUC-SP, graduada em medicina (UFPR). E-mail: roseleb@terra.com.br.
} 


\section{INTRODUÇÃO}

O conteúdo deste artigo se baseia na minha tese de doutorado em Filosofia que teve por objetivo compreender a formação do discurso médico, conforme abordado por Michel Foucault em seu livro $O$ Nascimento da clínica $(N C)$, de 1963. O foco do interesse de Foucault pela medicina pode ter vindo da sua atuação no hospital psiquiátrico, e também durante as pesquisas nas bibliotecas de medicina ao escrever História da loucura, sua tese que fora publicada apenas dois anos antes.

$\mathrm{Na}$ trajetória filosófica de Foucault, o livro $N C$ elabora uma arqueologia do olhar médico, porque no seu projeto arqueológico ele explorava historicamente quais as convergências que constituíram as formações discursivas na modernidade, no limiar dos séculos XVIII e XIX. A pesquisas arqueológicas foucaultianas encontram sua originalidade justamente em considerar as descontinuidades históricas e descrever as formações discursivas e suas verdades no interior das contingências, dos acontecimentos e dos acasos de cada época. Portanto, para Foucault, a racionalidade médica tal como a conhecemos hoje nasceu naquele momento histórico preciso.

A primeira frase do "Prefácio" de $N C$ avisa o que viria nos seus capítulos: "este livro trata do espaço, da linguagem e da morte; trata do olhar" (FOUCAULT, 2008a). O olhar médico seria a expressão que sintetizava a forma objetiva e penetrante que o saber médico assumiria na modernidade. Em sua formação, como se acompanha no desenvolvimento do livro, esse saber médico seria constituído mediante a lógica de uma linguagem descritiva que poderia enunciar a verdade científica; a partir dos espaços que esse olhar explorava, e pelos princípios da anatomia patológica na dissecção dos cadáveres. A linguagem médica é um dos princípios do método clínico, visto que se trataria de um discurso descritivo dos elementos da doença ou da anatomia do corpo e suas alterações, para obter o conhecimento da doença. O método clínico se valeria da descrição detalhada daquilo que o exame médico vê, partindo da lógica ingênua de que ver e dizer é conhecer. A morte era abordada na constituição do método clínico principalmente por meio da anatomia patológica de Javier Bichat, em que a dissecção dos cadáveres viria a fundamentar o conhecimento anatômico das doenças e o funcionamento do corpo vivo. Foucault não deixa de perceber este paradoxo, que é conhecer a vida, por meio da morte.

Na sua abordagem filosófica dos saberes, Foucault fez várias investigações sobre os espaços, sua arquitetura e seu funcionamento. Seus estudiosos sugerem que Foucault 
privilegiava nas suas análises a espacialidade, e não a temporalidade, mesmo quando delimitava as rupturas entre determinadas épocas, por exemplo, ao tratar dos solos dos conhecimentos possíveis em cada época.

Neste artigo, vou deter-me apenas na questão dos espaços que o saber médico explorou, especialmente em explicitar como a medicina se disseminou para os espaços públicos, fato que estava ligado ao tema da saúde da população. Portanto, para Foucault, essa dispersão do saber médico para outras áreas e as suas implicações no papel que o médico passou a exercer perante a sociedade foram uma das condições que constituíram a medicina moderna.

\section{MEDICINA DAS EPIDEMIAS}

Esquematicamente, conforme o pensamento de Foucault em $N C$, o saber médico moderno se constituiu por meio de certa geometria discursiva dos corpos e de uma geografia da doença.

$\mathrm{Na}$ geometria dos corpos, a analítica de Condillac fora a inspiração para o estabelecimento de uma lógica orgânica descritiva que se fundava em ver e dizer a doença, sendo que a anatomia patológica estabeleceu as relações de geometrização no interior dos corpos. Esses modelos ligavam o saber do indivíduo à sua própria finitude, e foram inicialmente os principais fundamentos para o positivismo da medicina.

Na geografia da doença, pode-se acompanhar a experiência médica em três espaços privilegiados: (1) no corpo anatômico; (2) no hospital e, (3) no espaço social. Com a expansão do campo de ação do discurso médico, novas formas de relações discursivas se estabeleceram e outros fundamentos foram adicionados à positividade da medicina, é o que se verá em seguida.

No capítulo II de NC, "Uma consciência política", Foucault analisa como o acontecimento das epidemias fez com que a medicina do século XVIII voltasse definitivamente o seu olhar para os fenômenos gerais da população e redobrasse o seu espaço de atuação para regiões geográficas mais extensas do que o hospital. Era a cidade inteira que deveria ser o objeto do saber, não somente o indivíduo doente. Embora não se reconhecesse muito bem como os "miasmas" e os "fermentos" poderiam transmitir a febre maligna, a varíola, a disenteria, entre outras, essa não era uma questão fundamental para a medicina da época, porque a epidemia era tida como a ação de uma causa geral e singular que se abatia acidentalmente uma vez em um local, por exemplo, Marselha em 1721, Bicêtre em 1780, Rouen em 1769, Paris em 1785. Então, foi a problematização das epidemias que fez com que as análises populacionais e os fenômenos 
climáticos, topográficos, físicos, higiênicos, de distribuição local devessem ser observados, descritos, controlados, regulamentados.

Foucault afirma que no final do século XVIII outra forma de experiência da medicina estava em vias de se institucionalizar e de se constituir, porque a observação das epidemias exigia o treinamento de um olhar múltiplo de vigilância, novos conceitos e novas abrangências.

Aparecem instituições do Estado que irão regulamentar o exercício social da medicina: a polícia sanitária e a Sociedade Real de Medicina. A polícia sanitária tinha funções ambientais de fiscalização da salubridade das instalações, do comércio, dos cemitérios etc., em todo o território da província; também funções educacionais, porque deveria orientar as pessoas desde o modo de se vestir, de se alimentar, como agir para evitar e curar as doenças; e, por fim, tinha como tarefa controlar o trabalho dos médicos. A Sociedade Real de Medicina, criada por um decreto de 1776, e composta por médicos cujo principal mentor fora Vicq d'Azyr, tinha o papel de estudo amplo das epidemias, elaboração dos fatos, controle e prescrição das medidas indicadas aos médicos e à população. Ela acabou tornando-se o órgão oficial, com recursos e poder político, para fazer emergir uma nova consciência social da medicina.

Pelo lado da constituição do saber, a medicina das epidemias se oporia, portanto, à medicina classificatória anterior, que era baseada na percepção individual de uma essência mórbida, porque agora se trata de analisar uma série de casos, integrá-los no tempo e no espaço, comparar, decifrar, buscar analogias e coerências que possam determinar a causa. Trata-se também de distribuir e educar as pessoas, e ainda controlar os médicos para prestar assistência e informações. Nas palavras de Foucault, ambas, contudo, partilhavam o novo aspecto político e social da medicina, como se lê a seguir.

E, no entanto, no final das contas, quando se trata das figuras terciárias, que devem distribuir a doença, a experiência médica e o controle do médico nas estruturas sociais, a patologia das epidemias e a das espécies se encontram diante das mesmas exigências: a definição de um estatuto político da medicina e a constituição, no nível de um estado, de uma consciência médica encarregada de uma tarefa constante de informação, controle e coação; exigências que "compreendem objetos tanto relativos à polícia quanto propriamente da competência da medicina". (FOUCAULT, 2008a, p. 27).

E a seguir, ele continua.

A Sociedade [Real de Medicina] não agrupa mais apenas os médicos que se consagram ao estudo dos fenômenos patológicos coletivos; tornou-se o órgão oficial de uma consciência coletiva dos fenômenos patológicos; consciência que se 
manifesta, no nível da experiência como no nível do saber, tanto de forma cosmopolita quanto ao espaço da nação. (FOUCAULT, 2008a, p. 29).

Foucault assinala que essa nova consciência coletiva foi um acontecimento que mudou a percepção médica e, assim, tornou-se uma das condições de possibilidade do saber médico moderno. Foi a medicina das epidemias que possibilitou o fortalecimento desse espaço que vai da percepção do doente às medidas do Estado. Nesse momento, fica clara a emergência dessa consciência política que, aliás, dá nome ao capítulo.

\section{2 "UMA CONSCIÊNCIA POLÍTICA"}

Foucault (2008a, p. 30) resume as características desse exercício médico, político e social como um "novo estilo de totalização". O movimento de totalização descrito por Foucault inclui vários pontos importantes, conforme os parágrafos a seguir.

O modelo de saber torna-se um quadro aberto e indefinidamente prolongável. Um trabalho coletivo de vários olhares que introduzem numerosas séries paralelas sobre temas indefinidos. Observações sobre as doenças, o clima, a água, o ar, o terreno, descrição de casos etc. são motivo de observação e de descrição. Não se trata mais de uma reorganização exaustiva em um quadro fechado.

As informações devem ser constantes e sempre atualizadas em direção a uma percepção geral infinita, não mais um conhecimento enciclopédico em busca de uma sistematização final.

$\mathrm{Na}$ trama complexa das séries que se entrecruzam é que o conhecimento se dá, onde o médico pode reconhecer o caso individual. Deve-se acompanhar as reflexões de Foucault no extrato a seguir.

\footnotetext{
O que constitui agora a unidade do olhar médico não é o círculo do saber em que ele se completa, mas esta totalização aberta, infinita, móvel, sem cessar, deslocada e enriquecida pelo tempo, que ele percorre sem nunca poder detê-lo: uma espécie de registro clínico da série infinita e variável dos acontecimentos. Mas seu suporte não é a percepção do doente em sua singularidade, é uma consciência coletiva de todas as informações que se cruzam, crescendo em uma ramagem complexa e sempre abundante, ampliada finalmente até as dimensões de uma história, de uma geografia, de um Estado. (FOUCAULT, 2008a, p. 31).
}

Quando se colocam em destaque esses fatores, observa-se que o encontro do médico com o doente está intermediado por um olhar médico que procura circunscrever a patologia individual dentro de uma rede de informações. Veja-se ainda: 
O que define o ato do conhecimento médico em sua forma concreta não é, portanto, o encontro do médico com o doente, nem o confronto de um saber com uma percepção; é o cruzamento sistemático de várias séries de informações homogêneas [...] mas cuja interligação faz surgir, em sua dependência isolável, o fato individual. (FOUCAULT, 2008a, p. 32).

O olhar médico deverá estar presente generalizadamente no espaço social, ele será, ao mesmo tempo, o ponto de convergência de uma rede múltipla de vigilância e o ponto de difusão do saber adquirido. Os médicos serão implantados em todos os lugares do departamento, para recolher, prestar informações e conduzir a saúde da população.

Entra em jogo o conhecimento estatístico da saúde e da doença, reforçando a matematização do saber médico. A estatística emerge, porque é preciso controlar os fatos populacionais e os ataques mórbidos. Pede-se o registro dos nascimentos, das mortes, das razões de reformas etc. Deve-se, enfim, estabelecer uma "topografia médica" completa de cada região. Acompanhe-se a seguir:

\begin{abstract}
Coloca-se o problema da implantação dos médicos no campo, deseja-se um controle estatístico da saúde, graças ao registro dos nascimentos e das mortes (que deveria mencionar as doenças, o gênero de vida e a causa da morte, tornando-se assim um estado civil da patologia); pede-se que as razões de reforma sejam indicadas em detalhe pelo conselho de revisão; finalmente, que se estabeleça uma topografia médica de cada departamento "com cuidadosos sumários sobre a região, as habitações, as pessoas, as paixões dominantes, o vestuário, a constituição atmosférica, as produções do solo, o tempo de sua maturidade perfeita e de sua colheita, assim como a educação física e moral dos habitantes da região"1. (FOUCAULT, 2008a, p. 33).
\end{abstract}

E novamente o conhecimento parece tender para um espaço essencial e exterior ao indivíduo, localizado no cruzamento dos registros, nas séries estatísticas. Não mais no nível dos sinais e dos sintomas e de seu tratamento, mas no nível das análises das informações numéricas, biológicas, seriais, reticulares, globais, que tentam diagnosticar e antecipar o futuro.

O médico será o conselheiro higienista, chamado para opinar na vida das pessoas. A educação e o ensino devem ser reforçados para que cada indivíduo aprenda a vigiar a sua saúde. Mais uma vez, é importante reler: "E como se não bastasse a implantação dos médicos, pedese que a consciência de cada indivíduo esteja medicamente alerta; será preciso que cada cidadão esteja informado do que é necessário e possível saber em medicina.” (FOUCAULT, 2008a, p. 33).

\footnotetext{
${ }^{1}$ Foucault está citando J.-B. Demangeon, Des moyens de perfectionner la médecine, Paris, ano VII, p.5-9; cf. Audin Rouvière, Essai sur la topographie physique et médicale de Paris. Paris, ano II.
} 
Portanto, o espaço do exercício médico se constituiu de uma consciência política, pois sua ação não se restringe ao indivíduo, mas se conforma à vida coletiva da nação.

E, no entanto, essa nova totalização controladora da saúde se estabeleceu sobre os mitos de um "campo livre" do sonho revolucionário. A medicina viu-se revestida de dois mitos, Foucault explica, o da profissão médica institucionalizada, militante e dogmática, que atacaria a doença em todos os lugares; e o mito de um desaparecimento total da doença, em que a sociedade se veria livre de todos os males, vícios e paixões, sendo que a saúde seria a consequência de um retorno à vida simples e natural. Foi apenas um sonho, contudo isso levou a uma inflexão no saber médico e também nos mecanismos políticos para controlar a saúde da população. Como outra consequência, novos parâmetros surgiram para o conhecimento médico, especialmente a preocupação em manter os indivíduos saudáveis e a preocupação com o homem normal. Esse quadro se manteria até o século XIX quando, do conceito regulador de "saúde", passa-se à noção de "normalidade", pois o conhecimento passará a se pautar no tipo de funcionamento da estrutura orgânica normal. E, então, as ciências do homem se desenvolverão no caminho das ciências da vida, porque permanecerão apoiadas na biologia, mas também na medicina, e assim trarão a polaridade do normal e do patológico em seu interior. Veja-se uma conclusão importante de Foucault.

\footnotetext{
Se as ciências do homem apareceram no prolongamento das ciências da vida, é talvez porque estavam biologicamente fundadas, mas é também porque o estavam medicamente: sem dúvida por transferência, importação e, muitas vezes, metáfora, as ciências do homem utilizaram conceitos formados pelos biólogos; mas o objeto que elas se davam (o homem, suas condutas, suas realizações individuais e sociais) constituía, portanto, um campo dividido segundo o princípio do normal e do patológico. Daí o caráter singular das ciências do homem, impossíveis de separar da negatividade em que apareceram, mas também ligadas à possibilidade que situam, implicitamente, como norma. (FOUCAULT, 2008a, p. 39).
}

Delaporte (2011) explica que, para Foucault, a medicina clínica emergiu de um contexto cultural e do seu meio socioeconômico, sendo que fazer a sua história requereu uma análise sincrônica das coerências e das noções da época. A Revolução Francesa foi um acontecimento exterior, mas que partilhou com o discurso médico a mesma mentalidade e o mesmo ambiente cultural, inclusive os mesmos paradoxos. Um dos elementos constitutivos da clínica foi uma "consciência política que toma a forma de uma consciência médica generalizada", levando ao surgimento de "uma medicalização militante da sociedade" que "liga as questões da medicina ao destino dos Estados" (DELAPORTE, 2011, p. 338, tradução nossa). A medicina não será mais somente um conjunto de técnicas e conhecimentos que buscam a cura das doenças, ela 
passará a se preocupar também com a saúde dos indivíduos. A preocupação com uma concepção de saúde requeria o estabelecimento dos critérios de normalidade e, também, a investigação dos modelos fisiológicos normais. Portanto, o projeto de uma medicina de Estado levou a uma organização do saber médico em torno da normalidade, mais do que em torno dos critérios de conhecimentos verdadeiros ou falsos. Delaporte (2011, p. 339, tradução nossa) conclui que a política não impôs, mas sim abriu "novos campos de referência para os objetos da medicina, por exemplo: a população, os registros estatísticos, o controle médico no exército ou as instituições de assistência hospitalar”.

Portanto, no nível arqueológico, pode-se reconhecer que as transformações da medicina fizeram parte de contingências e rupturas no próprio solo do conhecimento e do funcionamento das práticas discursivas. No contexto, as condições de possibilidade do saber médico moderno abrangeram as relações discursivas com outros campos institucionais, políticos, sociais, científicos. Essas relações fizeram com que o saber médico se dispersasse e passasse a exercer a sua positividade em toda a sociedade. Porque há também um sentido de positividade que se refere aos conteúdos positivos, aqueles que têm o poder de afirmação sobre as coisas e devem ser compartilhados. "A saúde substitui a salvação", Foucault (2008a, p. 219) cita essa afirmação do médico e historiador da ciência José Miguel Guardia, na "Conclusão" de $N C$, para resumir o poder que a medicina terá na sociedade moderna.

\section{RELAÇÕES ESTRATÉGICAS}

Cabe ainda reconhecer outro movimento presente nesse capítulo II de $N C$, "Uma consciência política", que é a forma como o texto se vincula a trabalhos posteriores de Michel Foucault. Esse capítulo é o momento indicativo do caminho adiante, o das análises de Foucault acerca da genealogia dos poderes.

No livro coletivo publicado em 1976, As máquinas de curar: as origens do hospital moderno, sobre o mesmo tema dos hospitais e das transformações políticas e econômicas do final do século XVIII, Foucault escreve um capítulo cujo título é “A política da saúde no século XVIII” (FOUCAULT, 1979) ${ }^{2}$. Nesse texto, observa-se que ele acrescenta uma camada às análises das reformas da medicina no século XVIII, porque surgem em relevo as estratégias de

\footnotetext{
2 Tradução parcial deste capítulo está no texto “A política da saúde no século XVIII”, no livro Microfísica do poder (FOUCAULT, 2008b). Contudo remeterei sempre ao texto original, com tradução nossa.
} 
poder. Os médicos deixam de ter o protagonismo das reformas políticas, e as análises passam a se dar no nível global e anônimo das racionalidades que procuram sistematizar a saúde coletiva, as quais Foucault chamará de "política de saúde" (FOUCAULT, 1979, p. 7, tradução nossa) 3 . Enfatiza que a questão importante para ele fora como, num momento dado e em uma sociedade definida, a interação individual entre o médico e o paciente pode se articular com uma intervenção coletiva sobre a doença. E diz que a profissão médica, ou melhor, as "formas de profissionalização do médico" foram um bom ponto de partida (FOUCAULT, 1979, p. 7, tradução nossa $)^{4}$. Ele afirma que o século XVIII foi um momento importante para a medicina, pelas exigências quantitativas e qualitativas na formação dos médicos, pois fora preciso multiplicar o número de médicos e padronizar os cursos de medicina, vinculando os conhecimentos teóricos e os práticos. Os médicos também adquiriram mais prestígio, e a medicina se destacou de outras formas de cuidado com os doentes.

Foucault passa, então, a descrever a política de saúde do século XVIII, cujos discursos formariam os médicos a partir de então. Observa-se que ele a resume em consonância à consciência política da medicina em $N C$ e pontua as suas principais características, como resumidas abaixo (FOUCAULT, 1979, p. 7-8).

- Uma expansão do objetivo projetado para abranger a prevenção de todas as doenças.

- Um desdobramento da noção de saúde em dois sentidos: tanto normativo, por se colocar em oposição à doença; quanto num significado descritivo, pois torna a saúde o resultado observável de um conjunto de dados (frequência das doenças, gravidade, duração, riscos).

- As variáveis determinantes são caracteristicamente de um grupo ou de uma coletividade: taxas de mortalidade, vida média, expectativa de vida, doenças epidêmicas ou endêmicas que atingem uma população.

- O desenvolvimento de intervenções que não são propriamente terapêuticas ou médicas, mas que interferem nas condições e nos modos de vida, na alimentação, no habitat, no meio, na forma de educar as crianças etc.

- Enfim, uma integração de certas práticas da medicina à gestão econômica e política, visando a racionalizar a sociedade. A medicina não é mais simplesmente uma técnica

\footnotetext{
${ }^{3}$ Leia-se: "une politique de santé".

4 Leia-se: "L'histoire de la 'profession' médicale ou plus exactement des différentes formes de 'professionnalisation' du médecin s'est révélée, pour analyser ces apport, un bon angle d'attaque".
} 
importante na vida e na morte dos indivíduos, ela passou a se integrar às decisões de conjunto, como um elemento essencial para manter e desenvolver a coletividade.

Nesse texto, Foucault afirma que os cálculos do poder político para gestão da população, da atividade dos indivíduos e da circulação das coisas e das pessoas visavam, além do bemestar, à utilidade para o trabalho. Tratava-se de intervenções refletidas, baseadas em saberes específicos que apoiavam as técnicas de gestão política e administrativa; ele enfatiza, por exemplo, as ações da polícia da saúde sobre o corpo social. Nesse mesmo texto, ele destaca três itens sobre os temas principais que se desenvolveram na política da saúde do século XVIII; são eles: (1) "o privilégio da infância e a medicalização da família"; (2) "a importância da higiene e o funcionamento da medicina como instância de controle social"; (3) "perigos e utilidade do hospital" (FOUCAULT, 1979, p. 11, 13 e 14, tradução nossa) ${ }^{5}$. Os médicos participaram desses três temas, seja no suporte às famílias ou atuando na saúde em geral e nos hospitais, ainda no campo das pesquisas de saúde, sendo subordinados ou fornecendo suporte e informações técnicas. Adicionalmente, participaram de forma cada vez mais numerosa em diferentes instâncias de poder, assumindo responsabilidades administrativas ou diretamente nos órgãos políticos. Foucault afirma que os médicos se beneficiaram dessa intensificação do poder médico na sociedade. Citando a seguir.

\begin{abstract}
Dessa interpenetração do político e do médico para a transmissão da higiene, o "excesso de poder" de que se beneficia o médico, comprova-se desde o século XVIII [...]. O médico torna-se o grande conselheiro e o grande expert senão na arte de governar, ao menos naquela de observar, de corrigir, de melhorar o "corpo" social e de mantê-lo em um estado de permanente saúde. E é sua função de higienista, mais do que seu prestígio de terapeuta que lhe assegura essa posição politicamente privilegiada no século XVIII e início do século XIX. (FOUCAULT, 1979, p. 14, tradução nossa).
\end{abstract}

Em outro texto, uma entrevista, "O olho do poder" (1977), Foucault relata que descobrira o Panopticon por meio dos estudos dos projetos arquitetônicos hospitalares, na segunda metade do século XVIII, especialmente aqueles após o incêndio do Hôtel-Dieu, em 1772 (FOUCAULT, 2008c, p. 209-27). Ele descreve o Panopticon como uma tecnologia de poder inventada por Bentham para assegurar a visibilidade e o controle do maior número possível de indivíduos, com o menor custo. O princípio vem do projeto arquitetural que reúne

5 “1. Le privilège de l'enfance et la médicalisation de la famille"; "2. L'importance de l'hygiène et le fonctionnement de la médecine comme instance de contrôle social” ; "3. Dangers et utilité de l'hôpital". 
uma construção com disposição em anel e uma torre de vigilância central. As celas periféricas no anel são transparentes, tornando os seus ocupantes constantemente visíveis, enquanto a torre central não permite visão da sua parte interna, sendo impossível verificar a presença ou a ausência do vigilante. Isso colocaria os ocupantes das celas sob vigilância constante, sem mesmo saber se estão sendo vigiados ou não, o que até acabaria por levar a um controle interiorizado do comportamento. Esse mecanismo poderia servir para vigiar um louco, um doente, um condenado, um operário ou um escolar.

\section{CONSIDERAÇÕES FINAIS}

Para concluir este artigo pode-se chegar a três considerações sobre a nossa leitura do capítulo II de $N C$, "Uma consciência política", e seus desdobramentos posteriores. A primeira delas é que a preocupação com a saúde da população e suas implicações científicas, sociais e políticas foram uma condição de possibilidade do saber médico moderno, tal como o conhecemos hoje. A partir dessa condição que abrangia o espaço social, acrescida de outras investigações do tipo de discurso médico objetivo e do aprofundamento corporal da anatomia patológica foi que se formou o "olhar médico", tal como Foucault se expressa acerca da medicina clínica moderna. Essa constatação de que o saber médico é constituído em seus fundamentos por outros campos discursivos, e mesmo se sobrepõe aos seus campos de atuação, afasta a pretensa neutralidade da medicina e matiza as suas verdades científicas.

A segunda consideração conclusiva é sobre a profissionalização do médico, porque é a partir de uma racionalidade objetiva, vigilante, unilateral e matematizada que se vêm constituindo os médicos nas faculdades e corporações. Ao perceber isso, torna-se possível e desejável uma reavaliação dessa formação, talvez acrescentando-se uma camada de crítica aos discursos, e outra camada para busca do genuíno diálogo atencioso com os pacientes. Seria mais interessante e mais animador poder ampliar os limites de uma nova experiência possível para a medicina na atualidade.

Por terceiro, pode-se dizer que o tema dos hospitais e da medicina das epidemias nesse livro publicado em 1963 se vincula às análises que Foucault realizará sobre o que ele denomina a "biopolítica" e a "normalização da sociedade", estabelecendo-se, assim, uma ponte de interesse com as investigações posteriores. Deve-se destacar que, se o governo da saúde da população parece ser um fato intransponível da nossa modernidade, visto que está nas condições de possibilidade dos saberes que nos continuem, pode-se mesmo assim questionar como os 
médicos poderiam desenvolver uma nova consciência política; e se interrogar sobre uma nova forma de estabelecer outros diálogos estratégicos que promovam uma reflexão crítica para uma racionalidade mais flexível e inclusiva.

\section{REFERÊNCIAS}

DELAPORTE, François. Foucault, l'histoire et l'épistémologie. In: L'Herne - Foucault. Cahier dirigé par Philippe Artières, Jean-François Bert, Frédéric Gros, Judith Revel. Paris: L’Herne, 2011. p. 335-41.

FOUCAULT, Michel. A política da saúde no século XVIII. In: Microfísica do poder. Tradução de José Thomaz Brum Duarte. Organização, introdução e revisão técnica de Roberto Machado. 26.ed. Rio de Janeiro: Graal, 2008b.

FOUCAULT, Michel. La politique de la santé au XVIII siècle. In: Les machines à guérir, aux origines de l’hôpital moderne. 2. ed. Bruxelles: Pierre Mardaga ed., 1979.

FOUCAULT, Michel. Naissance de la clinique. 7. ed. Paris: Quadrige/PUF, 2007.

FOUCAULT, Michel. O nascimento da clínica. Tradução de Roberto Machado. 6. ed. Rio de Janeiro: Forense Universitária, 2008a.

FOUCAULT, Michel. O olho do poder. In: Microfísica do poder. Tradução de Angela Loureiro de Souza. Organização, introdução e revisão técnica de Roberto Machado. 26. ed. Rio de Janeiro: Graal, 2008c. 